ÁLVARO GÓMEZ-GUTIÉRREZa

CARMELO CONESA-GARCÍA ${ }^{\text {b }}$

ASKOA IBISATE GONZÁLEZ DE MATAUCOc

PEDRO PÉREZ-CUTILLAS ${ }^{d}$

DANIEL PORTILLO-GRAU

FRANCISCO JOSÉ SEGURA-MÉNDEZ

\title{
POTENCIAL DE LAS IMÁGENES AÉREAS HISTÓRICAS Y LA FOTOGRAMETRÍA AUTOMATIZADA PARA ELABORAR MODELOS 3D DE CAUCES EFÍMEROS MEDITERRÁNEOS Y CUANTIFICAR CAMBIOS MORFOLÓGICOS
}

\begin{abstract}
RESUMEN
El estudio de la dinámica de los cauces efímeros mediterráneos (CEM) resulta de gran interés, al tratarse de sistemas geomorfológicos expuestos a importantes fluctuaciones recientes en los factores extrínsecos e intrínsecos que los gobiernan. Para obtener una aproximación a su modelo dinámico y comprender su adaptación a diferentes perturbaciones, resulta vital el desarrollo de estudios a una escala temporal adecuada (décadas). En este trabajo, se analiza el potencial de los fotogramas aéreos históricos

a Instituto Universitario de Investigación para el Desarrollo Territorial Sostenible, INTERRA, Universidad de Extremadura. Avenida de las Letras. 10003 Cáceres. alvgo@unex.es. http://orcid.org/0000-0002-2337-2638.

b Departamento de Geografía, Universidad de Murcia, Facultad de Letras. Campus de la Merced. 30001 Murcia. cconesa@um.es. http://orcid.org/0000-0002-3818-5421.

c Departamento de Geografía, Prehistoria y Arqueología, Universidad del País Vasco. C/ Tomás y Valiente, s/n. 01006 Vitoria-Gasteiz. askoa.ibisate@ehu.eus. http://orcid.org/0000-0002-9396-476X.

d Habitat Estudios Ambientales S. L. Avenida Don Juan de Borbón, 98. 30007 Murcia. pedrope@um.es. http:// orcid.org/0000-0003-1271-3895.

e Habitat Estudios Ambientales S. L. Avenida Don Juan de Borbón 98. 30007 Murcia. d.portillo@habitatea.es

f Habitat Estudios Ambientales S. L. Avenida Don Juan de Borbón 98. 30007 Murcia. fjsegura@ucam.edu
\end{abstract}

Fecha de recepción: 18-06-2021. Fecha de aceptación: 20-07-2021. 
y la fotogrametría automatizada para generar modelos 3D y ortofotografías de CEM en diferentes fechas y tratar de analizar cambios morfológicos a partir de ellos. Se seleccionaron, a modo de ejemplo, varios tramos de dos ramblas en la cuenca del Segura (rambla de Algeciras y rambla de Valdelentisco) y otros tres en un curso efímero de la cuenca del Ebro (barranco de Tudela). Se emplearon fotogramas de los denominados vuelo americano B (1956) y vuelo interministerial (1973-1986), junto con puntos de apoyo naturales registrados con un sistema de posicionamiento global (GNSS) para alimentar técnicas de fotogrametría automatizada (Structure-from-Motion $\mathcal{E}$ Multi-View Stereo) y producir nubes de puntos, modelos digitales de superficie y ortofotografías. Fue necesario llevar a cabo algunas adaptaciones del flujo de trabajo fotogramétrico convencional a las características de los fotogramas (inclusión de marcas fiduciales, utilización de máscaras, uso de puntos naturales, etc.). Los resultados arrojaron un error cuadrático medio de los productos cartográficos que osciló entre 0,62 y 0,85 m, con densidades volumétricas de las nubes de puntos resultantes de 1,03 a $4,47 \mathrm{pts} \cdot \mathrm{m}^{-3}$. Por lo tanto, este enfoque metodológico podría emplearse en el análisis de cambios relevantes $(>1 \mathrm{~m}$ ) y para la descripción morfológica de los cauces e integrarse con cartografía reciente para una mejor compresión de su dinámica.

PAlabras ClaVE: cauces efímeros mediterráneos, fotogrametría automatizada; fotogramas aéreos históricos; nubes de puntos; modelo digital de elevaciones; ortofotografía.

\section{POTENTIAL OF AERIAL HISTORICAL IMAGERY AND AUTOMATIC PHOTOGRAMMETRY TO PRODUCE 3D MODELS OF MEDITERRANEAN EPHEMERAL CHANNELS AND QUANTIFY MORPHOLOGICAL CHANGES}

\section{Abstract}

The dynamics of Mediterranean ephemeral channels (MEC) is an interesting geomorphological topic as the extrinsic and intrinsic factors influencing this geomorphic system have been exposed to important and recent changes. It is crucial to carry out studies of these systems at suitable temporal scales (e.g. decades) to understand the dynamics of the model and the adaptation to different perturbations. In this work, we test the suitability of archival aerial imagery and structure-from-motion photogrammetry (SfM) to produce 3D models and orthophotographs of MEC for different dates and to quantify morphological changes. Several reaches were selected from two representative MEC in the Segura River Catchment (Rambla de Algeciras y Rambla de Valdelentisco) and three from a MEC in the Ebro River Catchment (Barranco de Tudela). Archival aerial photographs from 1956 (dataset known as "vuelo americano B") and 1973-1986 (dataset known as "vuelo interministerial") together with natural ground control points (GCPs) surveyed by a Global Navigation Satellite System to fed SfM and produce point clouds, digital elevation models and orthophotographs. The classical SfM workflow was adapted to work with the archival aerial imagery, i.e. adding fiducial markers, masking the photographs, using of natural permanent GCPs, etc. The results showed a root mean square error in the cartographic products that varied from 0,62 to $0,85 \mathrm{~m}$ with volumetric point densities in the resulting point clouds from 1,03 to $4,47 \mathrm{pts} \cdot \mathrm{m}^{-3}$. Hence, the proposed methodological approach may be used to 
quantify important geomorphic changes $(>1 \mathrm{~m})$, to characterize the morphology of MEC in the past and to include the resulting cartographic products with today spatial information for a better understanding of the dynamics.

Keywords: Mediterranean ephemeral channels (MEC); Structure-from-Motion photogrammetry; historical aerial photographs; point clouds; digital elevation models; orthophotograph.

\section{INTRODUCCIÓN Y OBJETIVOS}

La comprensión de la dinámica de los sistemas geomorfológicos posee un gran interés desde la perspectiva del riesgo y en el contexto de cambio global actual. Muchos de los procesos que dan forma a la superficie terrestre muestran una dinámica episódica y esporádica, con cambios que acontecen en periodos muy reducidos y que se alternan con largas etapas de cierta estabilidad. Por este motivo, habitualmente es necesaria una ventana temporal de observación lo suficientemente amplia con el fin de lograr una correcta caracterización del fenómeno (Guerin et al., 2020). Este es el caso de los cauces efímeros de medios semiáridos, cursos en equilibrio dinámico, cuya morfología se ajusta a escala de sucesos de diferente magnitud y frecuencia (Conesa-García, 1995, 2005). En ocasiones, pueden dar la sensación de tener un equilibrio metaestable, cuando el sistema permanece relativamente estable durante un prolongado periodo seco de inactividad geomorfológica. Pero, a escalas de tiempo mayores (p. e., varios años o décadas), se suceden avenidas esporádicas y repentinas, a veces imprevisibles, cuyos efectos morfológicos, aun siendo diferentes en función de la alteración producida, se integran dentro del sistema en respuesta a un equilibrio energético cambiante.

Además de un periodo de observación amplio y con mediciones frecuentes, es necesario un registro preciso y denso de la superficie topográfica. Las tecnologías que permiten este registro intensivo vienen aplicándose desde hace una o dos décadas. Este es el caso de los sistemas de tecnología láser, tanto terrestre (TLS, del inglés terrestrial laser scanner) como aerotransportado (LIDAR, del inglés laser imaging detection and ranging) y de las técnicas de fotorreconstrucción fotogramétrica o fotogrametría automatizada.

La utilización de la fotogrametría automatizada o fotorreconstrucción en el ámbito de la geomorfología es relativamente reciente, con los trabajos de James \& Robson (2012) y Westoby et al. (2012) como precursores. Con los términos fotogrametría automatizada o fotorreconstrucción denominamos a un conjunto de técnicas que incluyen la clásica Structure-from-Motion (SfM; Ullman, 1979) y desarrollos más recientes como Multi-View-Stereo (MVS; Seitz et al., 2006) y que permiten obtener modelos tridimensionales de la realidad con fotografías adquiridas por cámaras convencionales y sin mayores requerimientos para la toma que un elevado recubrimiento de la superficie por reconstruir.

En la fotogrametría automatizada se resuelven de forma conjunta los parámetros internos de la cámara y la geometría de la toma a partir de información redundante de las imágenes a través del denominado bundle adjustment y sin la necesidad de puntos de control en este proceso inicial. Tras esta aproximación inicial al modelo de la cámara y la geometría de la toma, habitualmente se incluyen puntos de control en el modelo (lo que permite su escalado y georreferenciación) y se reajustan los 
parámetros de la cámara y la posición de cada toma en función de la precisión de estos puntos de control. Finalmente, los algoritmos MVS permiten llevar a cabo una densificación del modelo generando una nube de puntos densa. Esta nube de puntos densa es el producto final habitual, si bien la mayor parte del software fotogramétrico incorpora como últimos pasos del flujo de trabajo la generación de un modelo digital de superficie (MDS), un modelo digital de elevaciones (MDE, a partir del tratamiento del MDS) y una ortofotografía.

Por todo lo anterior, la fotogrametría SfM-MVS o automatizada presenta importantes ventajas frente a otras técnicas de adquisición de datos topográficos: el proceso fotogramétrico requiere un menor control del usuario, su precisión es similar a la de los métodos más precisos existentes hoy día (como el escáner láser terrestre o TLS; Nouwakpo et al., 2016), su coste es muy bajo, el trabajo en campo se desarrolla en un breve espacio de tiempo, es una técnica no invasiva y no es necesario situarse sobre la topografía que se desea modelizar.

Debido a todas las características que hemos mencionado de la fotogrametría automatizada, ha sido una técnica ampliamente utilizada por los geomorfólogos para producir modelos tridimensionales de diferentes elementos y llevar a cabo la cuantificación de cambios o el análisis de la dinámica superficial (Alfonso-Torreño et al., 2019, 2021; Cucchiaro et al., 2018). En el caso específico de los cauces, el trabajo precursor de Gómez-Gutiérrez et al. (2014) mostrará que estas técnicas pueden utilizarse para cuantificar el volumen de suelo erosionado en cabeceras de cárcavas y obtener un modelo espacial de los cambios acaecidos. En este trabajo también se plantea la posibilidad de utilizar la fotogrametría automatizada alimentada con fotografías de archivo o preexistentes y que no fueron adquiridas para tal fin. Así, esta posibilidad de aplicación retrospectiva se convierte en otra ventaja frente a métodos como los basados en tecnología láser. Sin embargo, esta aplicación retrospectiva de la fotogrametría automatizada debe realizarse con cautela, ya que las fuentes existentes de fotografía aérea histórica suelen mostrar una geometría de la toma ideada a partir de los conceptos de la fotogrametría clásica, fundamentalmente la estereoscopia, que demandaba requerimientos de solape longitudinal del $60 \%$ y transversal del $20 \%$. Sin embargo, las técnicas SfM-MVS demandan que cada elemento sea visible en un elevado número de fotogramas, por lo que resultan adecuados solapes efectivos transversales y longitudinales de al menos el 80 \% y el 60 \% respectivamente. Además, la utilización de fotogramas con ejes de la toma paralelos, típicos en la fotogrametría clásica, puede dar lugar a errores sistemáticos tipo domo en los modelos resultantes (James \& Robson, 2014). Pese a todo esto, el procesado de fotogramas con los nuevos algoritmos de correspondencia de imágenes y densificación permite obtener nubes de puntos mucho más densas que facilitan y mejoran la reconstrucción de la topografía pretérita (Mölg \& Bolch, 2017).

Incluso las colecciones de fotografía terrestre de elementos geomorfológicos pueden estar bastante lejos de la geometría ideal necesaria para la elaboración de modelos tridimensionales con técnicas SfMMVS. Por ejemplo, Gómez-Gutiérrez et al. (2014) mostraron una clara disminución de la precisión atribuida a la pérdida de la geometría convergente de la toma y, sin embargo, los resultados presentaron la calidad suficiente para llevar a cabo la cuantificación del volumen erosionado entre estas fotografías de archivo y otras recientes. Pese a estos condicionantes, los ejemplos de aplicación retrospectiva de 
la fotogrametría automatizada en el estudio dinámico de las formas son numerosos: glaciares (Mertes et al., 2017; Mölg \& Bolch, 2017) y morfologías asociadas (Tonkin et al., 2016), acantilados costeros (Warrick et al., 2016) y procesos gravitacionales (Guerin et al., 2020), morfologías volcánicas (GomezGutiérrez, 2014) y en el ámbito de la erosión por cárcavas (Gomez-Gutiérrez et al., 2014) y la geomorfología fluvial (Bakker \& Lane, 2017).

En el caso específico de los cauces efímeros, resulta de particular interés la aplicación de técnicas que permitan mejorar la caracterización de su dinámica. Por lo tanto, este trabajo plantea como objetivo analizar el potencial de los fotogramas aéreos históricos y la fotogrametría SfM-MVS para generar productos cartográficos en diferentes fechas y tratar de analizar cambios morfológicos a partir de ellos. La utilidad de imágenes de archivo podría presentar un gran potencial; sin embargo, la opacidad de la mayor parte del software de fotogrametría automatizada hace difícil la evaluación de la precisión de los productos cartográficos obtenidos para usuarios sin conocimientos avanzados en fotogrametría (Brutto \& Meli, 2012; Remondino et al., 2014). Es justo en esta línea donde el presente trabajo pretende arrojar cierta luz. De manera específica, se analizaron los fotogramas del denominado vuelo americano B (1956-57) y del vuelo interministerial (1973-1986). La selección de estos vuelos se realizó sobre la base de la relevancia que presentan por las fechas de adquisición y de la escala de realización del vuelo. Pese a que el ámbito de los vuelos seleccionados es nacional, debe mencionarse que desde mediados del pasado siglo existen en la mayor parte de los países del mundo registros similares de fotografía aérea histórica (Cowley \& Stichelbaut, 2012).

\section{MATERIAL y MÉTODOS}

\section{Áreas de estudio}

Los tramos de estudio seleccionados pertenecen a tres cauces efímeros de la vertiente mediterránea: dos localizados en el sureste peninsular (rambla de Algeciras y rambla de Valdelentisco) y uno en la cuenca del Ebro (barranco de Tudela) (figura 1). La rambla de Algeciras drena una cuenca de $44,56 \mathrm{~km}^{2}$, con predominio de calizas en cabecera y margas en el área restante. El predominio de terrenos blandos ha propiciado el desarrollo de una densa red de cárcavas y barrancos, que configuran un paisaje de badland típico. La cuenca de la rambla de Valdelentisco $\left(22,52 \mathrm{~km}^{2}\right)$ participa de las características geológicas de las sierras litorales del oeste de Cartagena dentro del dominio bético interno. Su clima es semiárido, con prolongados periodos secos que alternan con sucesos aislados de lluvias torrenciales. La cubierta vegetal se compone de matorrales y arbustos xerófilos y las aguas de avenida pueden desarrollar una alta energía y velocidad. Durante los sucesos mayores suelen acarrear ingentes cantidades de sedimentos, sobre todo materiales de fondo de tamaños muy variados (arenas, gravas y cantos), y producir cambios notables en las formas del lecho y en la geometría del cauce principal.

Como tramos de cauce de referencia (TCR) se eligieron tramos con mayor potencial de cambio geomorfológico y mayor accesibilidad para la colocación de puntos de control. Los tramos elegidos en la rambla de Algeciras (medio-bajo y bajo) están muy próximos entre sí, pero muestran unos patrones 
de cambio morfológico diferentes, debido a la mayor o menor influencia del embalse situado aguas abajo en función de su distancia. En el caso de la rambla de Valdelentisco, se seleccionó el tramo medio por representar mejor las variaciones en el balance de sedimentos y los ajustes morfológicos dentro del cauce principal. El tramo inferior tiende a presentar cambios globales menos definidos, al ser producto del desbordamiento de las aguas de avenida, que afectan a un amplio lecho activo de inundación. De hecho, la elección del TCR medio en esta rambla permite reflejar la clara influencia que los tamaños de grano grueso y la carga de fondo, como modalidad de transporte dominante, tienen en el balance de sedimentos dentro del propio cauce. Aguas abajo, a lo largo del tramo inferior hasta la desembocadura, el cauce se ensancha muy considerablemente y la ratio anchura/profundidad (w/d) aumenta de forma extraordinaria, lo que haría más compleja e infructuosa la detección de cambios morfológicos verticales significativos.

\section{La rambla de Algeciras}

Los TCR medio-bajo $(3,2 \mathrm{~km})$ y bajo $(3 \mathrm{~km}$ ) elegidos en la rambla de Algeciras (en adelante AL-MB y AL-B) están muy próximos entre sí $(500 \mathrm{~m})$, lo que ha permitido abordarlos como un único tramo durante el procesado fotogramétrico (figura 1b). Ambos tramos corresponden a meandros profundamente encajados en margas del Neógeno, cuya evolución ha estado dominada por etapas de incisión y relleno desde época pre-Würm. Actualmente, muestran una actividad geomorfológica muy diferente a pesar de su proximidad. La distancia de ambos tramos respecto al embalse situado aguas abajo determina gran parte de las diferencias en la textura y formas del lecho. El tramo AL-MB, más alejado del citado embalse $(3,5$ a 6,7 km), muestra un lecho poco uniforme, con diversidad de geoformas (de incisión y deposición) y tamaños de partículas muy diferentes (figura 2a). Barras transversales y de meandro y pozas, son los rasgos geomorfológicos más característicos del lecho en este tramo. Las diferencias texturales entre barras y pozas y la desigual distribución de las velocidades de la corriente en las curvas de meandro siguen favoreciendo en la actualidad la erosión de los márgenes cóncavos externos, con el consiguiente incremento de la amplitud de onda de meandro. Los desplomes verticales de las paredes de los márgenes menos sinuosos coinciden con los sectores ocupados por barras medias transversales, compuestas de materiales gruesos (gravas y cantos), que ofrecen gran resistencia al excavado lineal (figura 2b). El tramo AL-B, situado inmediatamente aguas arriba del embalse de Algeciras, presenta un cauce de fondo plano o poco irregular, con sedimentos de tamaño más fino (limos, arenas y gravas) y una cubierta vegetal ripícola algo más densa (figura 2c). Su menor pendiente y la elevación del nivel de base local, asociado a la altura de las aguas de avenida en la entrada del embalse, tienden a suavizar las formas del lecho y promueven la acreción sedimentaria vertical en todo el tramo.

En este cauce se estudiaron dos tramos, denominados medio-bajo y bajo (en adelante, AL-MB y AL-B).

\section{La rambla de Valdelentisco}

El tramo medio seleccionado en la rambla de Valdelentisco tiene una longitud total de 2,3 km y consta de dos subtramos de referencia (TCR medio alto y TCR medio bajo) (figura 1c). El primero 
$(1,5 \mathrm{~km})$ es un tramo parcialmente confinado, entre estructuras de edad Pérmico-Triásica y depósitos detríticos de ladera de origen Cuaternario. El cauce adopta forma de artesa, un índice de encajamiento moderado-alto, una ratio anchura/profundidad en torno a 8 y una ratio de incisión baja $(<1,2)$. El lecho se compone de una barra longitudinal central activa (arenas y gravas) y una barra lateral de materiales más gruesos (gravas, cantos y bloques, cubiertos por una delgada capa de limos). El TCR medio bajo $(800 \mathrm{~m}$ ) lo constituye un cauce ancho de amplio radio de curvatura y un desarrollo lateral promovido por el ensanchamiento del fondo del valle. En todo su recorrido presenta índices bajos de encajamiento e incisión, y ratios de anchura/profundidad muy altas (w/d > 25). La importante carga de fondo transportada y los aportes laterales de material grueso procedentes de barrancos tributarios de fuerte pendiente han originado un cauce trenzado poco profundo de perímetro curvo. Desde el Plioceno, ambos tipos de aportes vienen convergiendo en esta zona de forma sincrónica (barras sinsedimentarias) o alterna (depósitos superpuestos). Los antiguos lóbulos y lenguas de derrame depositados por las aguas torrenciales de los barrancos fueron recortadas por paleoinundaciones de la rambla, que conformaron potentes barras aluviales, actualmente relictas e inactivas. Adyacentes a estas, se ha desarrollado un sistema de barras entrecruzadas, que actualmente reconducen las aguas de avenida hacia los márgenes del cauce, ensanchándolo aún más (figura 2c y d).

\section{El barranco de Tudela}

El barranco de Tudela, también denominado San Gregorio, se localiza en la depresión del Ebro y al sur de las Bardenas Reales, compuesto por materiales continentales depositados durante el Mioceno. La apertura de la cubeta hacia el mar Mediterráneo posibilitó la inserción de la red de drenaje del río Ebro, erosionando sus materiales. Los tramos estudiados se ubican en el curso medio-bajo del barranco de Tudela. Cada TCR tiene 2170, 1950 y 890 m, respectivamente. El barranco está insertado en calizas y margas grises del Mioceno, que conforme van descendiendo al tramo bajo dan paso a arcillas y margas. En el TCR de Tudela alto el cauce está encajado entre escarpes verticales donde afloran estratos calizos entre los materiales arcillosos. Ello se refleja en un tamaño del material del lecho grueso, con presencia de bloques calizos, bien procedentes de colapsos de los escarpes o del propio lecho al meteorizarse el lecho rocoso que puntualmente queda exhumado. Al tramo llegan dos barrancos por su margen derecha, el barranco de Rutia al inicio del tramo y el barranco de Valdelacruz cerca del fin de este. El valle se abre ligeramente al inicio del TCR medio, que se caracteriza por un lecho de fondo más plano y un tamaño de sedimento más pequeño. Presenta un trazado rectilíneo fruto de las cortas de varios meandros sucedidos a comienzos del siglo xxi y un cauce más estrecho. El TCR bajo, próximo a su desembocadura en el río Ebro, se encuentra adosado en su margen derecha al escarpe vertical que alcanza una importante altura (figura 2e). El cauce ha experimentado también una corta natural de un meandro. En el tramo se evidencia una mayor presencia de caudal fruto de los retornos de regadío de los cultivos del entorno; probablemente por ello también hay una mayor colonización vegetal del lecho. En general, se ha constatado un estrechamiento del cauce activo en todos los tramos, a excepción del TCR alto, donde se ha mantenido desde la primera imagen disponible de 1956. 


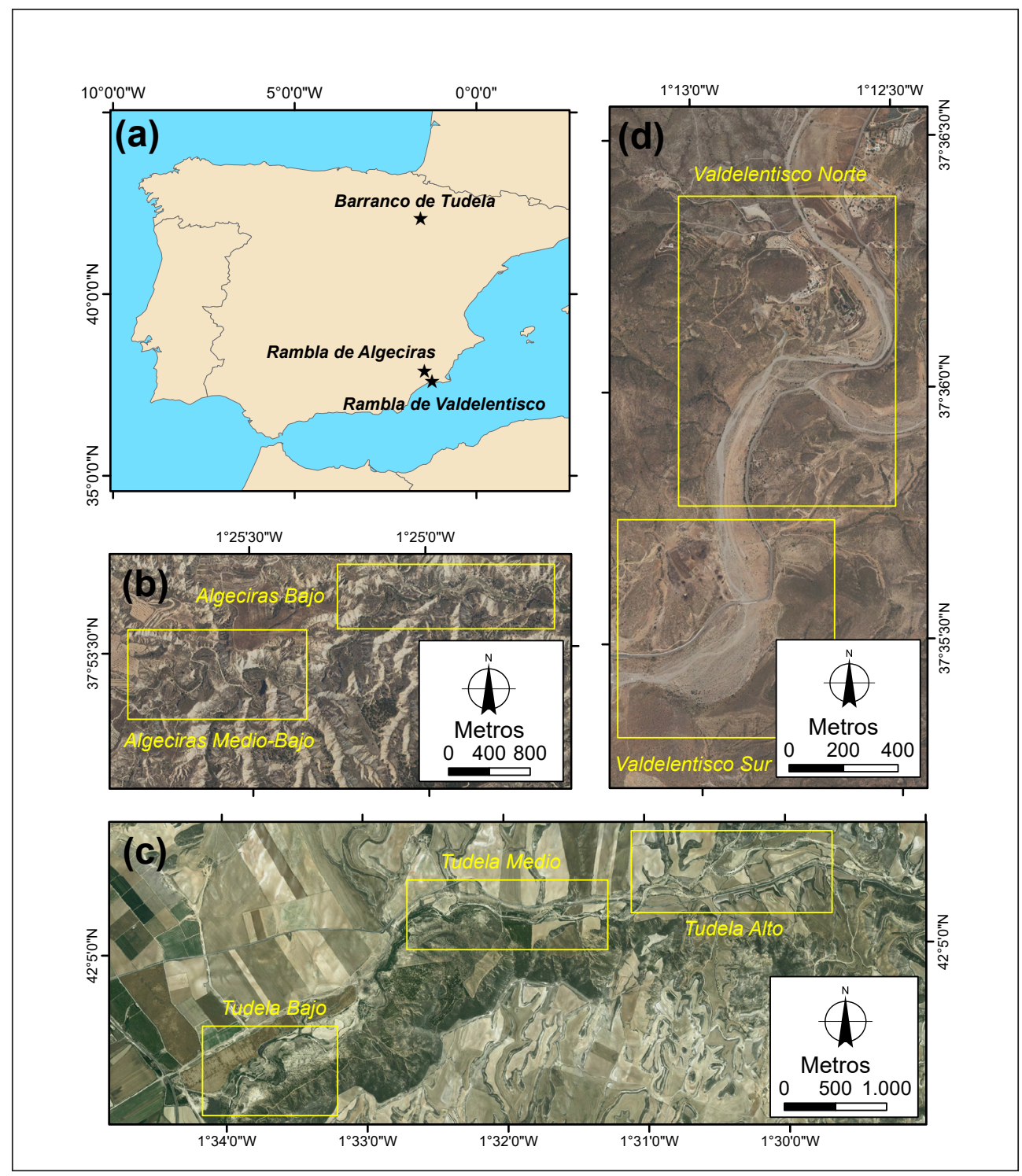

Figura 1. (a) Localización de las áreas de estudio en la Península Ibérica y detalle de los tramos estudiados en $(b)$ la rambla de Algeciras, $(c)$ la rambla de Valdelentisco y $(d)$ el barranco de Tudela. Fuente: CNIG; elaboración propia. 


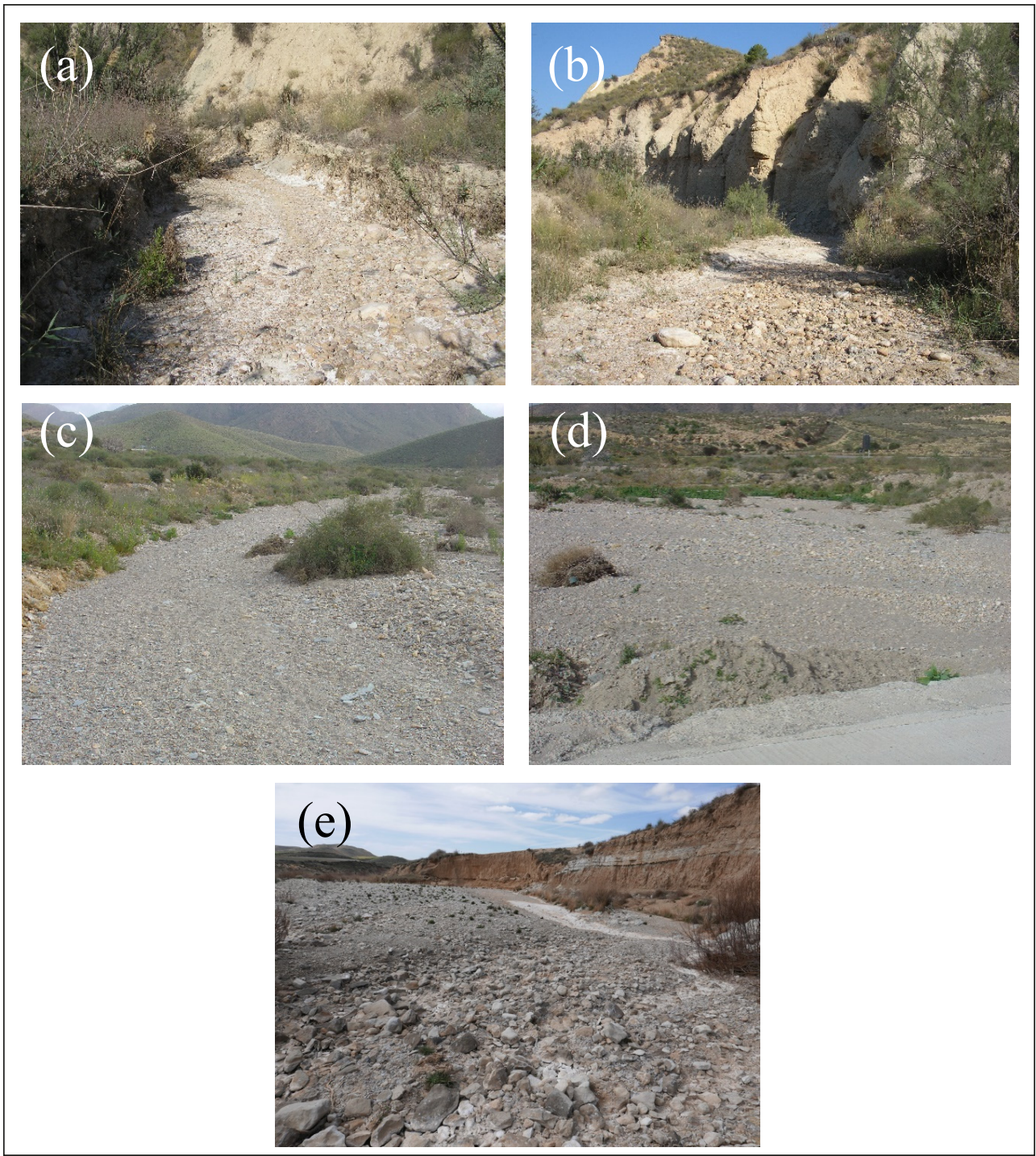

Figura 2. (a) Tramo medio-bajo de la rambla de Algeciras, con presencia de formas de relleno e incisión, $(b)$ barras activas transversales flanqueadas por paredes verticales de margas, $(c)$ tramo medio bajo de la rambla de Valdelentisco, con alta carga de fondo, donde el cauce actual de aguas bajas mantiene muy poca profundidad respecto a $(d)$ las barras entrelazadas y $(e)$ tramo medio-bajo del barranco de Tudela. 
Flujo de trabajo

\section{Fotogramas históricos}

La selección de los fotogramas para utilizar se realizó en función de sus características (resolución, disponibilidad, año de vuelo, etc.) y los objetivos propios del trabajo (fechas lo suficientemente espaciadas para caracterizar la dinámica de cada tramo a medio plazo). Se emplearon fotogramas del denominado vuelo americano B, escaneados con una resolución de $21 \mu \mathrm{m}$. La adquisición de los fotogramas del vuelo americano B se llevó a cabo durante los años 1956 y 1957 y se planificó para una escala de vuelo aproximada de 1:33.000. Para el segundo vuelo se emplearon fotogramas del denominado vuelo interministerial o IRYDA (Instituto Nacional de Reforma y Desarrollo Agrario), con una escala de vuelo de 1:18.000 y desarrollado entre los años 1973 y 1986, escaneados a 15 um. Este lapso de tiempo entre ambos vuelos permite caracterizar los cambios acaecidos en los cauces a una escala temporal de varias décadas.

Observación de los puntos de apoyo (GCP) mediante sistemas de posicionamiento global (GNSS)

En el procesamiento mediante fotogrametría SfM-MVS se hace necesario el empleo de puntos con coordenadas conocidas (GCP) si se desea escalar y georreferenciar el modelo. De modo que resulta habitual la inclusión de marcas artificiales en la zona de estudio de forma previa a la realización del vuelo en el que se capturarán los fotogramas. Sin embargo, la utilización de fotogramas aéreos históricos condiciona la selección de GCP, ya que deben ubicarse en elementos fácilmente identificables e inmutables desde la adquisición de los fotogramas hasta la actualidad. Para identificar los GCP sobre elementos naturales, se empleó un sistema de información geográfica (SIG) sobre el que se interpretó y superpuso información pretérita (mosaico de los fotogramas aéreos históricos) y actual, esto es, la ortofotografía aérea de máxima actualidad servida por el Centro Nacional de Información Geográfica (CNIG) dentro del Plan Nacional de Ortofotografía Aérea (PNOA) a través de un servicio WMS. De forma adicional, también se superpuso en dicho proyecto SIG información topográfica (Mapa Topográfico Nacional a escala 1:25.000) para la planificación del acceso a los GCP seleccionados y el establecimiento de ubicaciones para la base del sistema global de posicionamiento (o GNSS, del inglés global navigation satellite system).

Para el registro de coordenadas de los GCP se emplearon dos antenas GNSS Emlid Reach (base y rover) y el software ReachView sobre un smartphone con conexión a internet. Debido a la cantidad de GCP y la superficie que cubrir, se han empleado diferentes técnicas de posicionamiento, siendo la más común el empleo de una base propia precisa definida empleando una base permanente de instituciones públicas y la utilización de esta base para el envío de correcciones en tiempo real a nuestra otra antena (rover), esto es, en modo RTK (del inglés real time kinematic). También se ha empleado la técnica RTK con VRS, esto es, con una estación virtual de referencia cercana al rover. En lugares con cobertura y proximidad a estaciones permanentes GNSS del Instituto Geográfico Nacional o de las comunidades autónomas, se empleó directamente el rover recibiendo correcciones a través de internet de estas estaciones (de nuevo, en modo RTK). Finalmente, en algunas ubicaciones con problemas para establecer de forma precisa la base y recibir correcciones en tiempo real en el rover se emplearon técnicas PPK 
(post-processing kinematic), mediante las cuales se obtienen las coordenadas precisas del posicionamiento tras un posprocesado en gabinete que se alimenta de las efemérides precisas y de los archivos de registro del rover y de una base o estación permanente. Para el empleo de las técnicas PPK, se empleó el software libre de posprocesado RTKlib.

\section{Procesado fotogramétrico y análisis de los productos cartográficos resultantes}

El desarrollo de los trabajos se llevó a cabo mediante el software fotogramétrico Metashape Agisoft (v. 1.6.2) con algunas modificaciones sobre el flujo de trabajo clásico en SfM-MVS debido a la naturaleza histórica y analógica de la información de partida. En primer lugar, fue necesario el establecimiento de un sistema de coordenadas imagen sobre la base de la presencia de las marcas fiduciales. En segundo lugar, se llevó a cabo un recorte del área de interés con el fin de excluir del análisis fotogramétrico los marcos de los fotogramas, masas de agua o partes del fotograma rasgadas y que han sido pegadas de nuevo sobre el fotograma (alterando así la geometría de los elementos de geometría interna de la cámara). Finalmente, los fotogramas se agruparon en función del número de serie de la cámara de captura, disponible en la información marginal. Tras estas modificaciones derivadas de las características de la información de partida, las fases del procesado fueron similares a las de cualquier procesado fotogramétrico SfM-MVS y que han sido ampliamente descritas en la literatura (alineamiento, referenciación y reoptimización, generación de la nube de puntos densa y producción del MDS, MDE y de la ortofotografía). Durante el alineamiento se buscan puntos homólogos entre fotogramas, de modo que se trata de resolver la calibración de la cámara (distancia focal, punto principal y funciones de distorsión radial) y ubicar cada fotograma en su posición en el momento de la toma (traslaciones y rotaciones en los tres ejes). Después se incorporan los puntos de apoyo al modelo, definiendo su ubicación y se lleva a cabo una reoptimización del alineamiento en función de la ubicación de los puntos de apoyo. Este procedimiento permite refinar los parámetros de calibración de la cámara a partir de las mediciones precisas de las coordenadas de los puntos de apoyo.

En el siguiente paso se generan los mapas de profundidad y la nube de puntos densa utilizando un filtro agresivo para tratar de reducir el ruido en la nube de puntos resultante. Adicionalmente, en la generación de la nube de puntos densa se llevó a cabo un filtrado de los que aparecen en esta a partir del nivel de confianza de cada punto. Este nivel de confianza viene determinado por la cantidad de mapas de profundidad que se emplean en el cálculo de cada punto en la nube de puntos densa final. Se trata de un parámetro cuyo valor se sitúa en torno a 5-6 para fotogrametría automatizada convencional, donde el solape es abundante. Con fotogramas aéreos históricos este valor se estableció en $>3$, tratando de dar lugar a una nube de puntos densa para datos con menor solape del habitual. Finalmente, a partir de la nube de puntos densa se obtuvo el MDS, el MDE y la ortofotografía de cada zona de estudio y fecha.

Las coordenadas de los puntos de control, además de asistir en el proceso de autocalibración de la cámara y de registro del bloque, se utilizan para el cálculo de estadísticos que permiten realizar una estimación de la calidad de los productos cartográficos generados. Entre estos estadísticos se encuentran el error cuadrático medio (o RMSE, del inglés root mean square error). Adicionalmente, se emplean otros parámetros calculados durante el procesado fotogramétrico, como el número de puntos de enlace, 
el error de reproyección, la resolución (o GSD, del inglés ground sampling distance), la densidad de puntos por unidad de superficie y el número de puntos de enlace por imagen. También se llevó a cabo el cálculo de la densidad volumétrica de puntos en el software de visualización y análisis de nubes de puntos CloudCompare. Se trata de un parámetro fundamental cuando analizamos formas complejas y que pueden presentar paredes verticales, como es el caso de las márgenes de los cauces efímeros.

Análisis de los cambios

Los enfoques metodológicos existentes para la cuantificación de cambios morfológicos son muy diversos y deben adaptarse a las características de los datos y a la naturaleza del fenómeno estudiado y su dinámica. En los últimos treinta años, debido a la preponderancia del MDE como representación de la superficie topográfica, el estudio de los cambios se ha basado en la sustracción de MDE (Wheaton et al., 2010). Se trata de un enfoque muy simple que presenta limitaciones en superficies y morfologías complejas (al poder asignar solo una cota a cada posición planimétrica, esto es, un enfoque 2,5D) (GómezGutiérrez \& Goncalves, 2020) y es muy sensible a errores de corregistro (Qin et al., 2016). Debido al desarrollo de instrumental (tecnologías de base láser, vehículos aéreos no tripulados o UAV, GNSS) y a la disponibilidad de datos plenamente tridimensionales (fundamentalmente nubes de puntos), han proliferado los métodos de estimación de cambios plenamente tridimensionales. Entre estos métodos de estimación 3D el más ampliamente utilizado es el Multiscale Model-to-Model Cloud Comparison algorithm (M3C2; Lague et al., 2013). Se trata de un método que estima la distancia directamente entre nubes de puntos ( $\sin$ necesidad de generar una superficie auxiliar), para lo que se define un vector ortogonal (o normal) a partir de los puntos vecinos al punto problema. Este vector funcionará como eje de un cilindro cuyo radio será definido por el usuario y que servirá para calcular el centro de gravedad de cada nube para los puntos incluidos dentro del cilindro. Finalmente, se proyectará la posición del centro de gravedad de cada una de las dos nubes sobre el eje del cilindro y se calculará la distancia entre ambas proyecciones. Tanto la densidad de puntos como su rugosidad (variación sobre el plano de mejor ajuste) son empleados para llevar a cabo una cuantificación de la incertidumbre en la estimación de la distancia, de modo que solo se consideran cambios reales aquellas distancias superiores a la incertidumbre calculada. Para más detalles recomendamos al lector consultar el trabajo de Lague et al. (2013).

Por lo tanto, se empleó el método M3C2 implementado en el software CloudCompare para llevar a cabo la estimación tridimensional de los cambios entre las nubes de puntos obtenidas a partir de la fotogrametría SfM-MVS para cada fecha. A partir del análisis empírico de las nubes de puntos resultantes de la fotogrametría, se establecieron valores de 3 y $6 \mathrm{~m}$ para los vectores de cálculo de normales y del centro de gravedad en el algoritmo M3C2. Posteriormente, se llevó a cabo una rasterización de las distancias con el objetivo de obtener una representación clásica de los cambios y poder llevar a cabo una comparación con el método tradicional. Los cambios estimados mediante este enfoque fueron comparados con los obtenidos por el método "clásico" basado en la sustracción de los MDE y conocido como DoD (del inglés DEMs of Differences; Wheaton et al., 2010). En el caso de los DoD empleamos un nivel de detección de cambios uniforme, basado en los errores obtenidos durante el procesado fotogramétrico. 
Finalmente, la cuantificación de cambios se circunscribió a la extensión del cauce. Esta delimitación se llevó a cabo sobre la base de criterios hidrológicos empleando la lámina de agua para avenidas con un periodo de retorno de mil años. Dicha lámina fue calculada mediante un modelo hidrodinámico 1D (HEC-RAS) a partir de un MDE de alta resolución generado mediante fotogrametría SfM-MVS e imágenes adquiridas por un vehículo aéreo no tripulado.

\section{Resultados}

El resultado básico de cualquier procesado fotogramétrico automatizado (SfM-MVS) es la nube de puntos. La figura 3 muestra las nubes de puntos obtenidas para uno de los tramos estudiados en la rambla de Algeciras (tramo bajo). A partir de estas nubes de puntos se elaboran productos cartográficos que podemos clasificar como 2,5D, como el MDE y la ortofotografía. La figura 4 muestra ambos productos cartográficos para el mismo tramo de la rambla de Algeciras, tanto el obtenido para el vuelo americano B de 1956 (figura 4a y 4c) como para el vuelo interministerial de 1986 (figura 4b y 4d). En las nubes

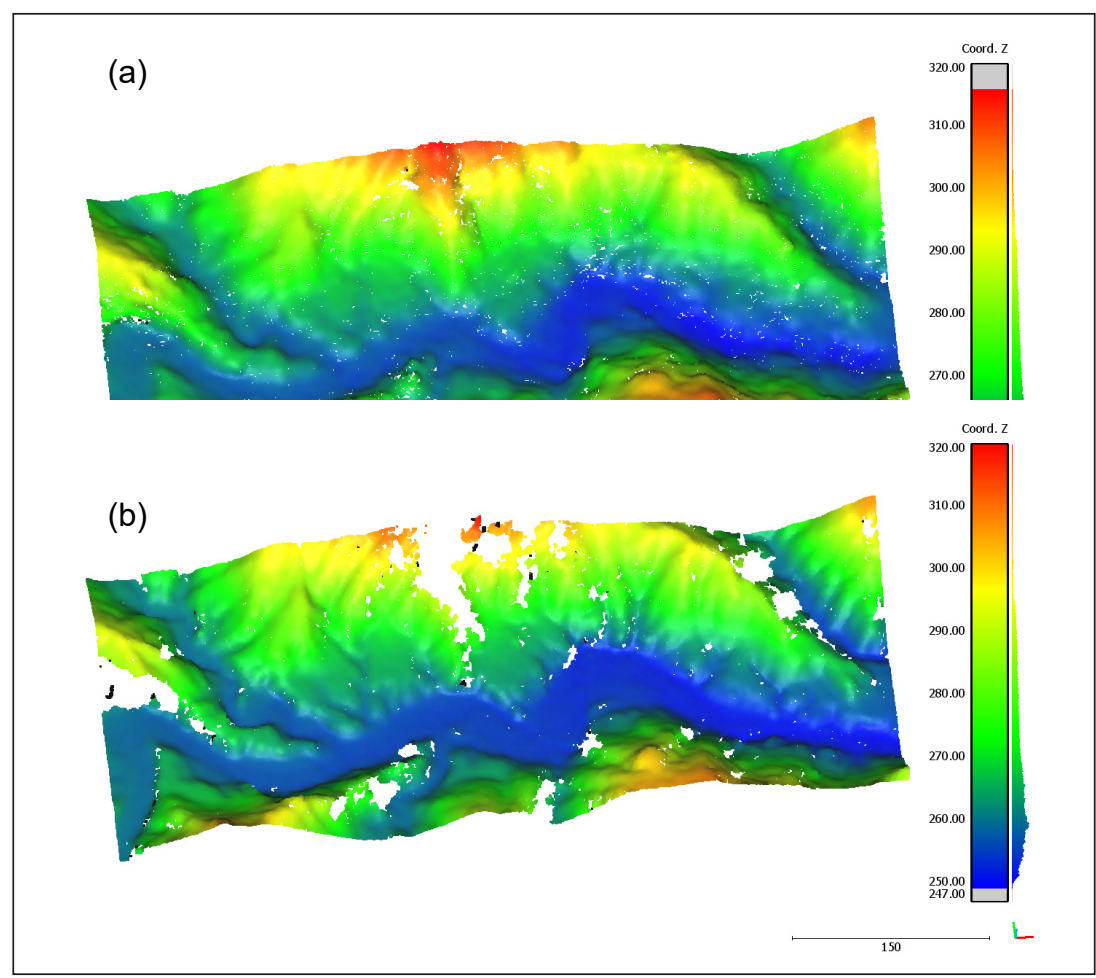

Figura 3. Nubes de puntos obtenidas del procesado fotogramétrico a partir de los fotogramas del (a) vuelo americano B y del (b) vuelo interministerial. 
de puntos se pueden observar notables diferencias en cuanto a densidad y cobertura (figura 3). El vuelo americano B muestra para esta zona de estudio un total de 110.990 puntos, frente a los 480.153 del vuelo interministerial; sin embargo, este último muestra una peor cobertura, con importantes superficies sin puntos (figura 3b). Estas zonas donde el procesado fotogramétrico no ha generado puntos deberán ser interpoladas para producir los MDE que aparecen en la figura 4a y $4 \mathrm{~b}$.

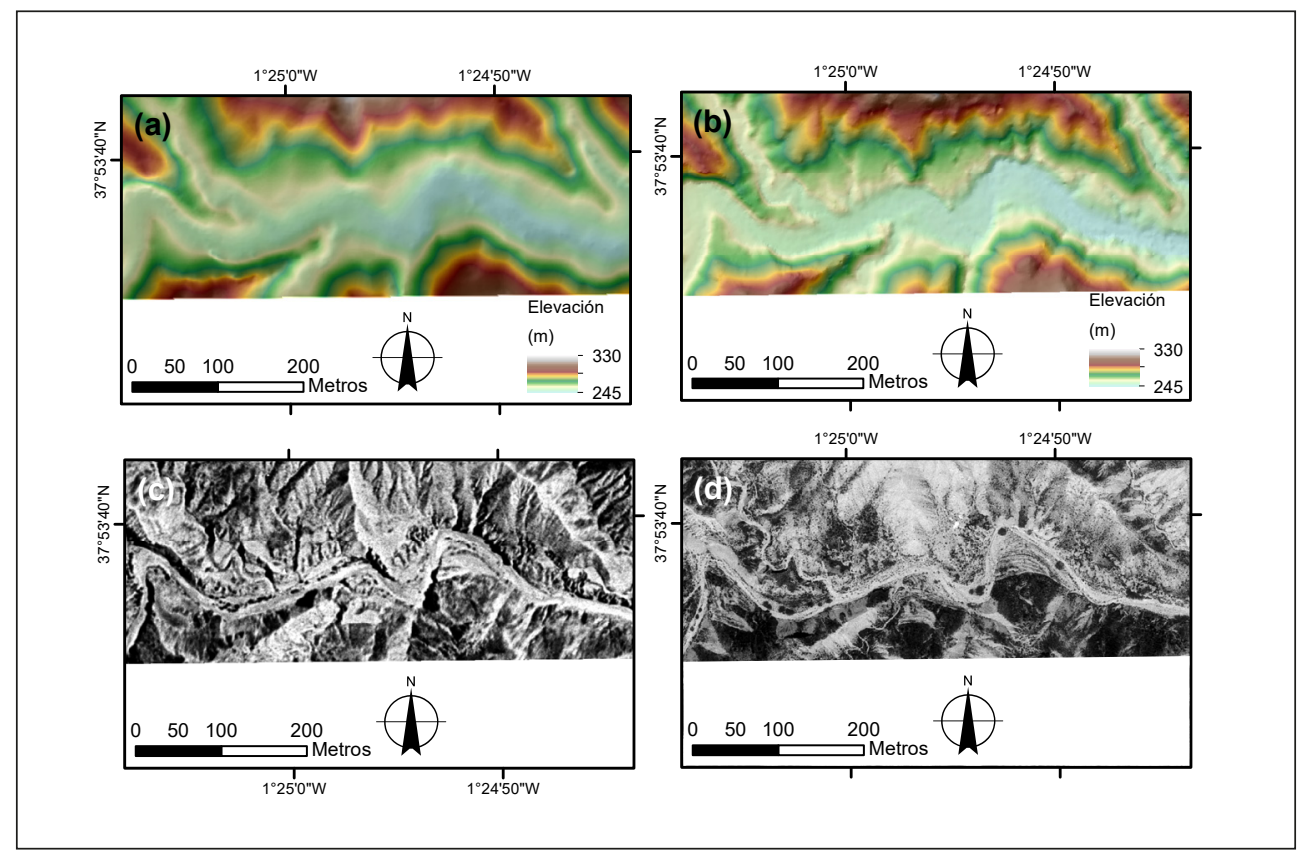

Figura 4. Modelo digital de elevaciones obtenido para (a) el vuelo americano B y $(b)$ el vuelo interministerial, y ortofotografía producida para el $(c)$ el vuelo americano B y $(d)$ el vuelo interministerial para el tramo bajo de la rambla de Algeciras.

Todos los parámetros de los productos cartográficos resultantes que guardan cierta relación con la escala de realización de los vuelos muestran evidentes diferencias para el vuelo americano B y el vuelo interministerial (tabla 1 y figura 5). De manera específica, observamos diferencias en la resolución espacial (figura 5a), la densidad planimétrica (figura 5c) y volumétrica de puntos (figura 5d) y el RMSE estimado para los GCP (figura 5e). El número de puntos de enlace por imagen identificados durante el procesado fotogramétrico también denota diferencias en la calidad de los fotogramas de ambos vuelos (figura 5b), ya que viene determinada no solo por la escala y técnica-metodología de captura, sino también por la conservación de los fotogramas y el tiempo transcurrido desde la adquisición. Incluso se aprecia una mayor variabilidad del número de puntos de enlace por imagen para un mismo vuelo, lo que indica la relevancia que el estado de conservación de cada fotograma o lote tiene sobre este factor (figura $5 b$ ). 
Tabla 1. Características de los datos de procesado fotogramétrico para cada zona de estudio y vuelo. De algunos parámetros, además del término en castellano se presentan los acrónimos en inglés, al tratarse de acrónimos de amplio uso: GSD = ground sampling distance, GCP = ground control point, RMSE = root mean square error. Inter.: interministerial.

\begin{tabular}{|l|c|c|c|c|c|c|}
\hline \multicolumn{1}{|c|}{ Cauce } & \multicolumn{2}{c|}{ Algeciras } & \multicolumn{2}{c|}{ Valdelentisco } & \multicolumn{2}{c|}{ Tudela } \\
\hline Vuelo & Ame. & Inter. & Ame. & Inter. & Ame. & Inter. \\
\hline Tramos & 2 & 2 & 2 & 2 & 3 & 3 \\
\hline Año & $1956-1957$ & 1986 & 1956 & 1986 & 1956 & 1986 \\
\hline Imágenes (n) & 12 & 3 & 17 & 4 & 6 & 6 \\
\hline $\begin{array}{l}\text { Resolución o GSD } \\
\text { (m-pix }{ }^{-1}\end{array}$ & 0,65 & 0,29 & 0,65 & 0,29 & 0,66 & 0,28 \\
\hline Puntos de enlace (n) & 417.917 & 335.198 & 815.227 & 395.400 & 71.597 & 565.808 \\
\hline $\begin{array}{l}\text { Puntos de enlace } \\
\text { por imagen (n) }\end{array}$ & 34.826 & 111.733 & 47.955 & 98.850 & 11.933 & 94.301 \\
\hline $\begin{array}{l}\text { Densidad de puntos } \\
\text { (ptos-m }{ }^{-2} \text { ) }\end{array}$ & 0,60 & 2,95 & 0,59 & 2,90 & 0,57 & 3,21 \\
\hline $\begin{array}{l}\text { Densidad volumétrica } \\
\left.\text { de puntos (ptos-m }{ }^{-3}\right)\end{array}$ & 1,15 & 4,47 & 1,03 & 4,17 & 1,03 & 4,42 \\
\hline Error de reproyección (píx) & 0,39 & 0,27 & 0,33 & 0,28 & 0,48 & 0,48 \\
\hline $\begin{array}{l}\text { Puntos de Control } \\
\text { o GCP (n) }\end{array}$ & 37 & 27 & 60 & 42 & 38 & 56 \\
\hline $\begin{array}{l}\text { Error cuadrático medio } \\
\text { o RMSE (m) }\end{array}$ & 0,85 & 0,54 & 0,62 & 0,62 & 0,67 & 0,62 \\
\hline $\begin{array}{l}\text { Error cuadrático medio } \\
\text { en X o RMSE (m) }\end{array}$ & 0,59 & 0,32 & 0,41 & 0,29 & 0,50 & 0,33 \\
\hline $\begin{array}{l}\text { Error cuadrático medio } \\
\text { en Y o RMSE (m) }\end{array}$ & 0,47 & 0,32 & 0,41 & 0,32 & 0,35 & 0,37 \\
\hline $\begin{array}{l}\text { Error cuadrático medio } \\
\text { en Z o RMSE (m) }\end{array}$ & 0,38 & 0,30 & 0,22 & 0,45 & 0,28 & 0,49 \\
\hline
\end{tabular}

Los fotogramas de ambos vuelos permitieron trabajar con resoluciones espaciales $<1 \mathrm{~m}$. El RMSE también mostró valores $<1 \mathrm{~m}$ para todos los casos, por lo que este umbral, el del metro, es un buen indicador de los cambios que podrían detectarse empleando los productos cartográficos obtenidos de la fotogrametría automatizada alimentada con los fotogramas de estos vuelos. El RMSE indicó una mayor consistencia en las estimaciones realizadas para el vuelo interministerial, con un rango de variabilidad de unos $10 \mathrm{~cm}$ frente al RMSE del vuelo americano B, que mostró una variación de más de $20 \mathrm{~cm}$. Es decir, los errores, además de ser inferiores, son más estables para el vuelo interministerial. Por el contrario, el RMSE estimado para el vuelo americano B resultó en valores absolutos mayores y en una mayor variabilidad de estos (figura $5 \mathrm{e}$ ). 

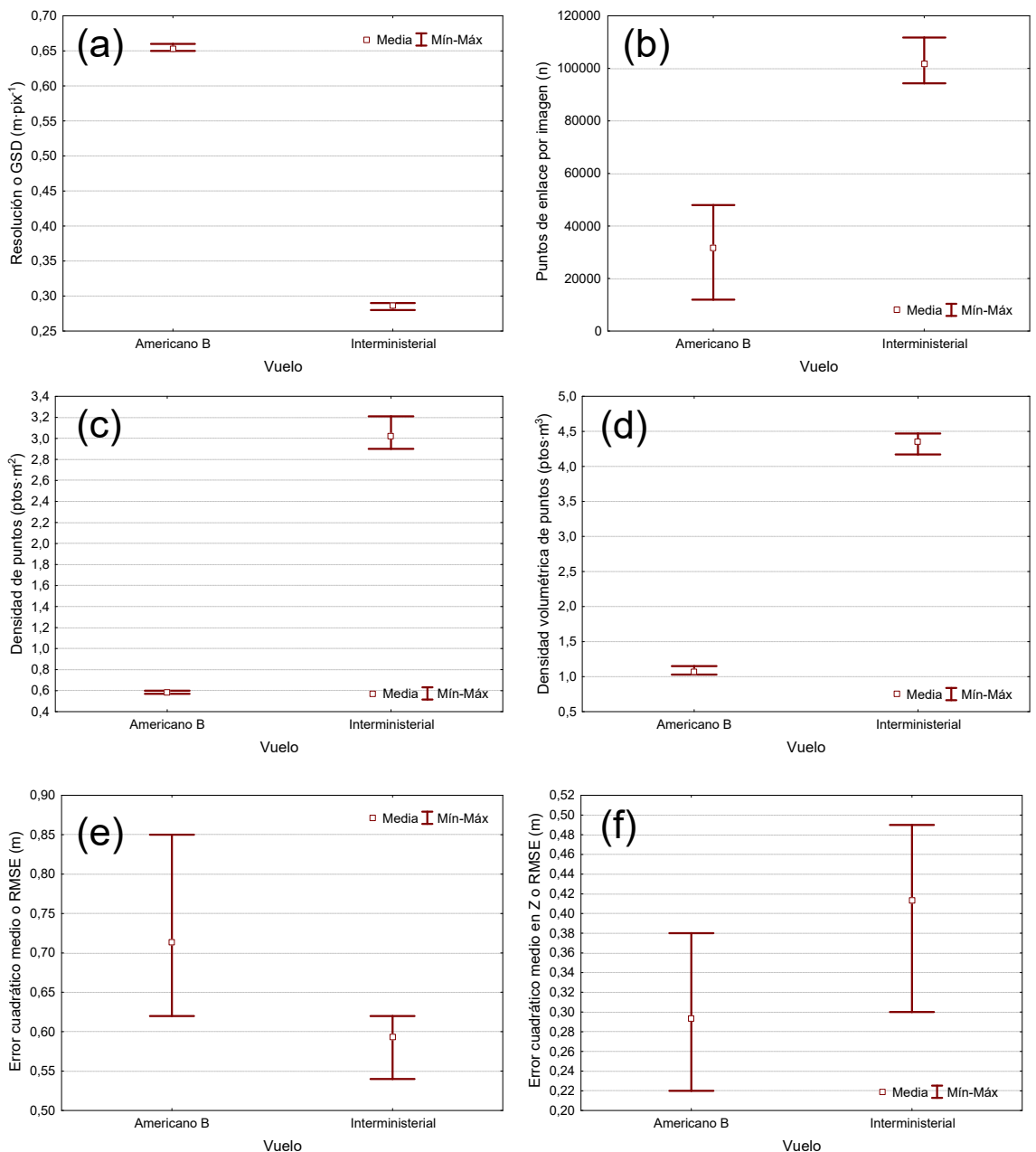

Figura 5. Diferencias entre el vuelo americano B y el interministerial para los siguientes parámetros de los resultados del procesado fotogramétrio: (a) resolución espacial o GSD (ground sampling distance), (b) puntos de enlace por imagen, $(c)$ densidad planimétrica de puntos, $(d)$ densidad volumétrica de puntos, $(e)$ error cuadrático medio o RMSE (root mean square error) y $(f)$ error cuadrático medio o RMSE en la coordenada Z. Mín-Máx: mínimo-máximo.

La densidad volumétrica de las nubes de puntos fueron aproximadamente 1 y $4 \mathrm{pto} \cdot \mathrm{m}^{-3}$ para el vuelo americano B y el interministerial, respectivamente. Estos datos nos muestran nubes de puntos con mayores densidades, por ejemplo, que las obtenidas mediante sensor LIDAR en las coberturas nacionales del Plan Nacional de Ortofotografía Aérea. 
Finalmente, resultó de interés que el RMSE en la coordenada Z mostró valores ligeramente superiores para el vuelo interministerial, al contrario de lo que cabría esperar (figura 5f).

El análisis por cauce mostró que no existen diferencias significativas en lo que respecta a la resolución espacial y las densidades de puntos (figura 6). Sin embargo, sí observamos algunas diferencias en otros parámetros. El número de puntos de enlace por imagen resultó ligeramente inferior para el cauce de Tudela (figura 6b). En Algeciras, se empleó un menor número de puntos de control debido a la inexistencia de estructuras permanentes y a la compleja orografía (figura 6c), y estos factores dieron lugar a un RMSE sustancialmente mayor en términos absolutos y con mayor rango de variabilidad (figura 6d).

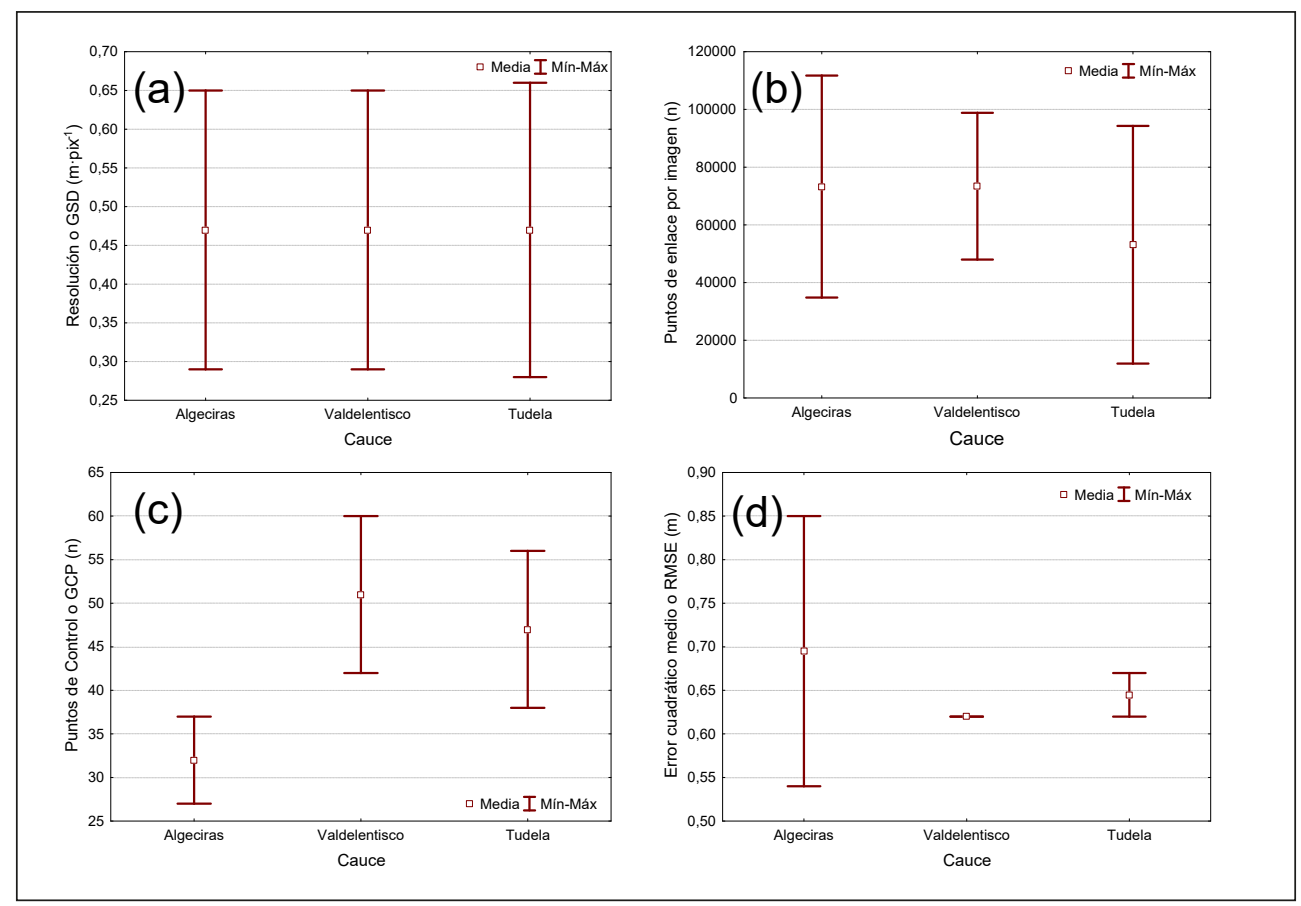

Figura 6. Diferencias por cauce para los siguientes parámetros de los resultados del procesado fotogramétrico: (a) resolución o GSD (ground sampling distance), (b) puntos de enlace por imagen, (c) puntos de control o GCP (ground control points) y (d) error cuadrático medio o RMSE (root mean square error).

Por lo que respecta a los cambios morfológicos registrados en los cauces entre las fechas de estudio, la técnica plenamente tridimensional M3C2 permitió una interpretación y representación de estos de gran utilidad (figura 7). En la rambla de Algeciras, por ejemplo, existe una coexistencia de procesos de 
erosión y deposición en el tramo medio-bajo (figura 7a) frente a un claro predominio de la deposición en el tramo bajo (figura 7b).

Las figuras 8, 9 y 10 muestran los cambios estimados mediante la técnica M3C2 (con representación en un SIG, esto es 2,5D, para facilitar la comparación) y la tradicional basada en DoD para los diferentes tramos de los cauces de la rambla de Algeciras, Valdelentisco y el barranco de Tudela, respectivamente. Todos los modelos elaborados permiten una interpretación basada en procesos sobre los cambios morfológicos acaecidos. Los cambios registrados por las dos técnicas para los diferentes tramos muestran patrones espaciales similares de pérdida y ganancia de material. No obstante, la estimación basada en el algoritmo M3C2 siempre resultó en superficies de cambio menores. Debemos señalar en este punto que los DoD utilizan un umbral mínimo de detección que se ha establecido en $1 \mathrm{~m}$, es decir, todos los cambios por debajo de este umbral no se consideran al estar dentro del margen de error estimado durante el procesado fotogramétrico. Este error es uniforme sobre la totalidad del área de estudio. Sin embargo, en el caso de los cambios M3C2, para cada punto en la nube se realiza un cálculo de la incertidumbre en la estimación de la distancia, siendo variable dentro del área de estudio. Pese a estas diferencias, los patrones espaciales de los cambios son consistentes entre métodos y coherentes con los procesos propios de los CEM (incisión, deposición, colapso de las márgenes, etc.).

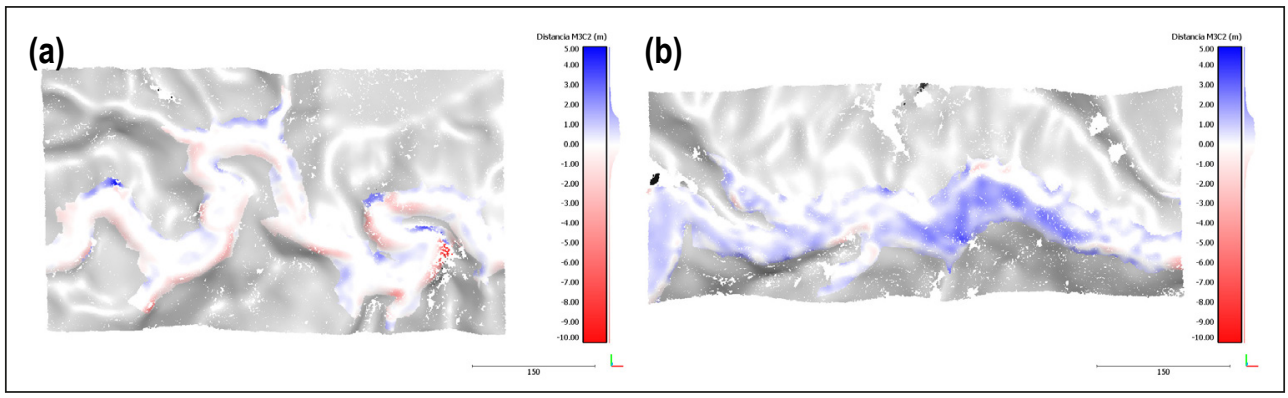

Figura 7. Distancias de cambio tridimensional M3C2 estimadas a partir de las nubes de puntos para el periodo 1956-1986 en el tramo (a) medio-bajo y (b) bajo de la rambla de Algeciras. En diferentes tonos de gris se representa el relieve 3D de la zona cercana al cauce objeto de estudio. 


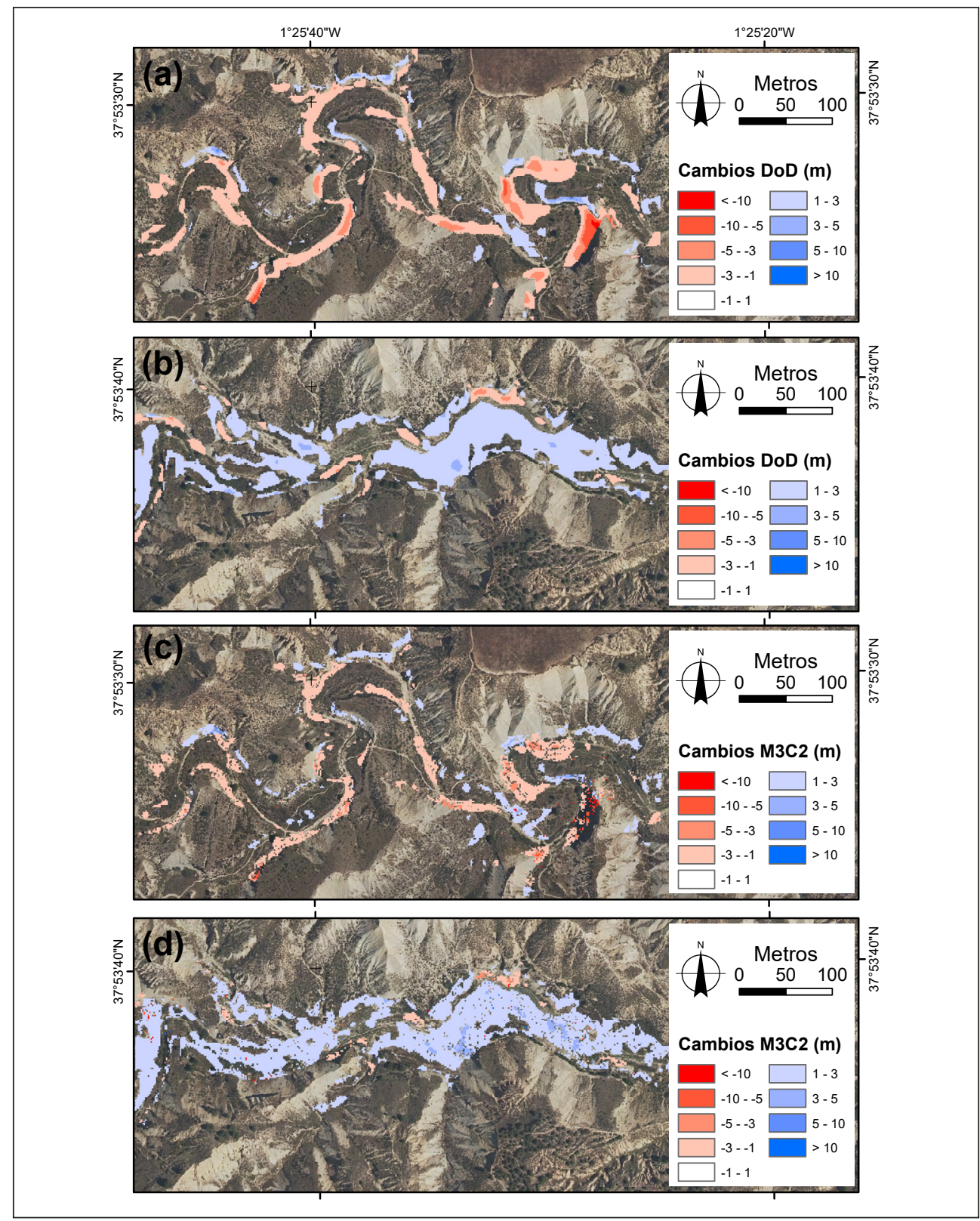

Figura 8. Cambios registrados en los dos tramos estudiados de la rambla de Algeciras para el periodo 19561986: (a) modelos digitales de diferencias (DEMs of Differences o DoD) para el tramo medio-bajo y $(b)$ el bajo, y (c) Multiscale-Model-to-Model-Cloud-Comparison (o M3C2) para el tramo medio bajo y (d) bajo. 

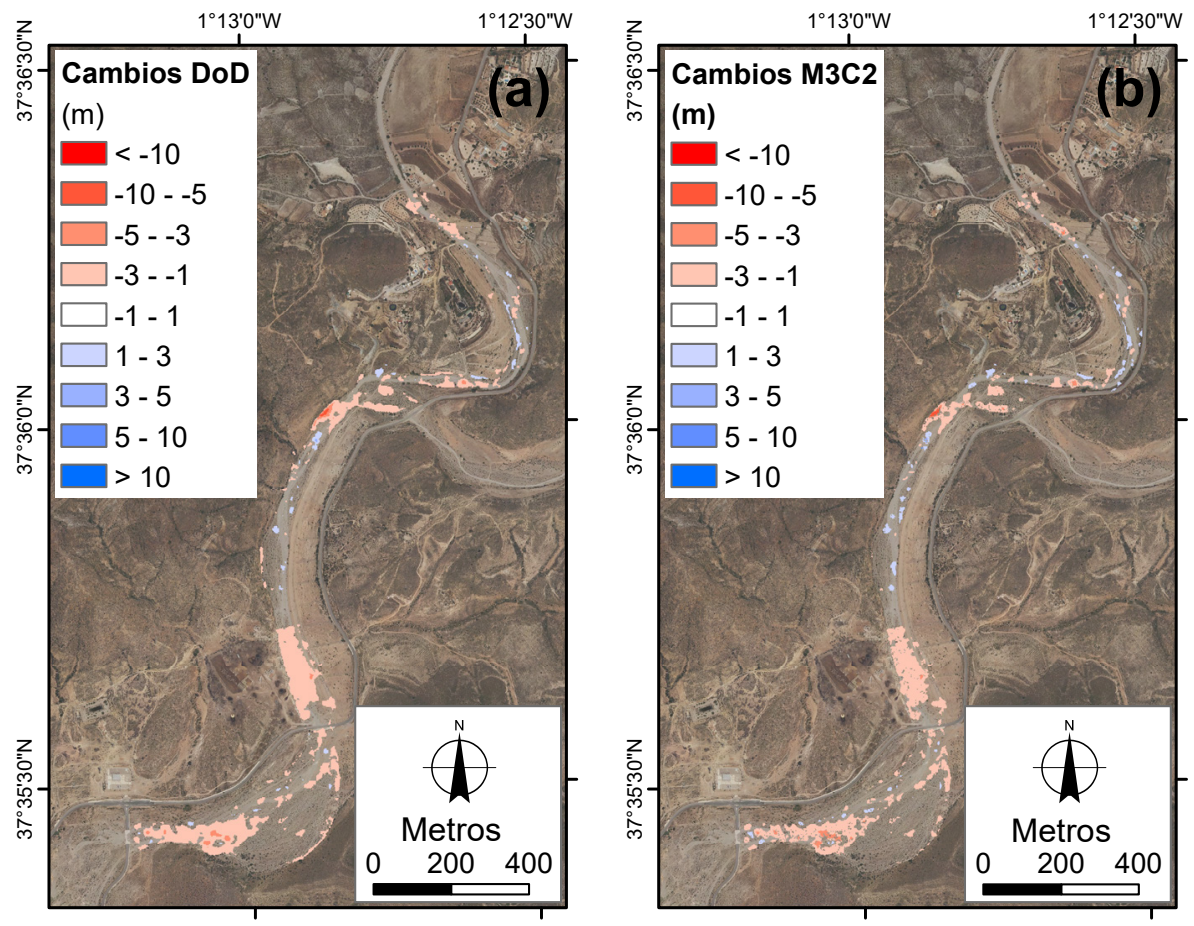

Figura 9. Cambios registrados en la rambla de Valdelentisco para el periodo 1956-1986 empleando la técnica (a) modelos digitales de diferencias (DEMs of Differences o DoD) y (b) Multiscale-Model-to-Model-Cloud-Comparison (o M3C2). 


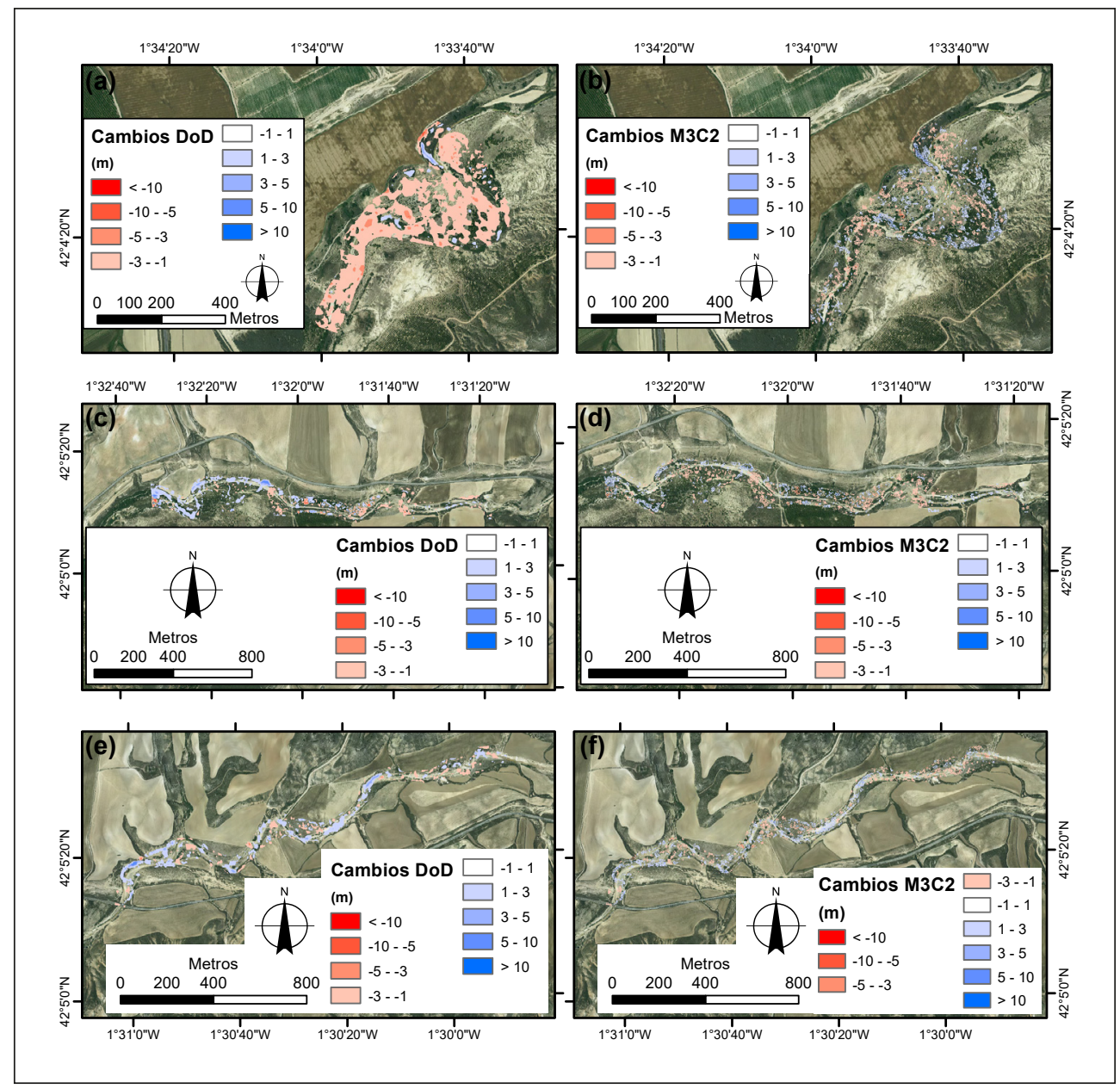

Figura 10. Cambios registrados en el barranco de Tudela para el periodo 1956-1986 para el tramo bajo empleando la técnica (a) modelos digitales de diferencias (DEMs of Differences o DoD) y $(b)$ Multiscale-Model-to-Model-Cloud-Comparison (o M3C2), para el tramo medio usando (c) DoD y (d) $\mathrm{M} 3 \mathrm{C} 2$ y para el tramo alto con $(e)$ DoD y $(f) \mathrm{M} 3 \mathrm{C} 2$.

\section{Discusión}

Los productos cartográficos elaborados a partir de las técnicas de fotogrametría automatizada alimentada con fotografías aéreas históricas mostraron calidad métrica, en línea con lo arrojado por otros trabajos de la misma temática (por ejemplo, Mertes et al., 2017). Por este motivo, la utilidad de los vuelos empleados aquí debe enmarcarse en el ámbito de formas relativamente dinámicas como los ambientes fluviales, glaciares o volcánicos (Eltner \& Sofia, 2020). El tiempo transcurrido entre los dos 
vuelos utilizados y las características de las zonas de estudio hacen, por lo tanto, que la metodología utilizada sea apropiada para el estudio de los CEM.

La mayor parte de los parámetros calculados muestran una calidad superior en los productos cartográficos generados a partir del vuelo interministerial, lo cual resulta obvio dadas sus características técnicas. Sin embargo, los resultados obtenidos a partir de los fotogramas del vuelo americano B deben considerarse de gran relevancia por la escala temporal de análisis que permiten. Las densidades volumétricas de las nubes de puntos generadas fueron mayores en ambos casos que las obtenidas en la primera cobertura nacional registrada con sensor LIDAR dentro del Plan Nacional de Ortofotografía Aérea. No obstante, debemos tener en cuenta que las nubes de puntos derivadas de la fotogrametría automatizada generan un MDS basado en la primera superficie visible, frente al pulso láser que permite capturar datos en presencia de cubierta vegetal. El MDS producido mediante fotogrametría automatizada necesita, además, ser filtrado para producir un MDE con la consiguiente pérdida de resolución y adición de errores. Además de la densidad de puntos, la cobertura fue relativamente homogénea. Sin embargo, el vuelo interministerial, pese a presentar una mayor densidad planimétrica y volumétrica de puntos, mostró zonas sin datos en la nube de puntos. Aquí se pone de manifiesto una importante limitación de los archivos de imágenes históricas, y es que la geometría de la toma fue diseñada a partir de los requerimientos de la fotogrametría clásica y no de la automatizada, que demanda un mayor solape (Bakker \& Lane, 2017); como consecuencia, las zonas reconstruidas con el vuelo interministerial, al desarrollarse a una mayor escala y menor altura, aparecen en un menor número de fotogramas, lo que da lugar a esas grandes zonas sin datos que a la postre deben ser interpoladas para generar el MDS y, finalmente, el MDE. Este hecho condiciona la selección de valores bajos del parámetro de nivel de confianza de los mapas de profundidad dentro del software de fotogrametría y propicia la existencia de un número pequeño de errores groseros, tal y como se debatirá más adelante.

Otra importante limitación observada durante el desarrollo de los trabajos es la concerniente a la adquisición de los GCP, que deben ser inmutables y en zonas cercanas a los cauces, lo cual supone un reto en zonas dinámicas donde los elementos están sometidos a alteraciones y obras de carácter hidrológico-forestal, cambios de uso como la puesta en cultivo u obras para riegos, graveras, etc. Además, la diversidad y extensión de las zonas de estudio hizo necesaria la utilización de diversas técnicas de registro y observación GNSS, lo que da lugar a variaciones en las precisiones de los GCP. El enfoque estándar de la fotogrametría automatizada se basa en la resolución de los parámetros de cada fecha-vuelo de forma individual y ha dado lugar a una tarea laboriosa y muy condicionada por la existencia de GCP. Frente a este enfoque, recientemente han visto la luz experiencias que fusionan en un mismo bloque-procesado imágenes aéreas históricas de diferentes fechas (Feurer \& Vinatier, 2018). De este modo, algoritmos como el Scale Invariant Feature Transform (SIFT; Lowe, 2004) pueden detectar elementos que se han mantenido inmutables a través del tiempo y mostrados con diferentes escalas, orientaciones, iluminación, ruido, etc. Esta técnica permite usar esa información contenida en imágenes de diferentes fechas para aproximar los parámetros de cada grupo de cámaras o imágenes utilizadas. Después, se independiza la producción de la nube de puntos densa y el MDS-MDE de cada fecha, de manera que los MDS-MDE resultantes minimizan los errores de corregistro que tanto afectan a la estimación de cambios (Bakker 
\& Lane, 2017) y usan la información de los elementos inmutables para mejorar los parámetros de calibración de cada cámara. La aproximación de los parámetros de cámaras para las que no existe un control geométrico (habitualmente no está disponible el certificado de calibración) es muy valiosa. Pero sin duda, la posibilidad de minimizar los errores de corregistro en zonas sin estructuras o elementos estables claramente identificables para el ojo humano (carreteras, edificios, etc.) supone un gran avance que se debe tener en cuenta en futuras experiencias. Como alternativa para la minimización de los errores de corregistro también se plantea el empleo de cartografía actual y metodologías intensivas de registro, como el algoritmo Iterative Closest Point (ICP: Besl \& McKay, 1992).

Respecto a la estimación de cambios y tal y como se ha mencionado en el apartado de resultados, el patrón fue similar para la técnica DoD y la M3C2, aunque esta última es más restrictiva. Trabajos recientes han mostrado que las técnicas basadas en métodos plenamente tridimensionales dan lugar a estimaciones más realistas de los cambios acaecidos, particularmente en ambientes morfológicamente complejos (Gómez-Gutiérrez \& Gonçalves, 2020). Estos mapas de cambios producidos han permitido además identificar un número pequeño, pero existente, de errores groseros (outliers) generados por puntos en las nubes con geometría incorrecta. Por ejemplo, cambios superiores a $10 \mathrm{~m}$ de deposición sobre márgenes verticales donde solo cabe experimentar erosión. La existencia de estos errores groseros se achaca al rebajamiento en el nivel de confianza de los mapas de profundidad que sirven para construir la nube de puntos. Este nivel se estableció en 3 cuando la fotogrametría automatizada convencional emplea valores de 6. De nuevo, la geometría de la toma condiciona este aspecto, ya que la utilización de valores convencionales daría lugar a una nube de puntos poco densa. La inclusión de normas lógicas en los modelos de estimación de cambios también podría ayudar en la mejora de los resultados obtenidos mediante esta técnica, minimizando estos errores groseros. Se trataría de normas basadas en el conocimiento experto que determinaría, por ejemplo, que sobre las márgenes con pendientes elevadas solo puede haber erosión en la parte alta, mientras que en la parte baja pueden experimentarse erosión por incisión lateral o deposición por colapso de la parte superior.

\section{Conclusiones}

Los productos cartográficos elaborados mediante fotogrametría automatizada alimentada con fotogramas aéreos históricos del vuelo americano B y el interministerial mostraron precisiones métricas. Tanto las nubes de puntos como los MDE resultantes se pudieron emplear para cartografiar los cambios acaecidos durante el periodo transcurrido entre los vuelos. La técnica DoD y la M3C2 mostraron patrones espaciales de cambio similares. Numerosos parámetros indicaron que el vuelo interministerial dio lugar a productos cartográficos de mayor precisión y calidad; sin embargo, su geometría de la toma derivada de una menor altura de vuelo resultó en nubes de puntos con una cobertura menos homogénea que las obtenidas a partir del vuelo americano B. La presencia/ausencia de GCP inmutables en las zonas de estudio también puede condicionar la aplicación de la metodología propuesta, lo que ha sido, en nuestro caso, una labor ardua. Para finalizar, debemos mencionar que publicaciones recientes señalan 
hacia un procesado multiépoca como alternativa a la toma de GCP para la estimación de cambios a partir de fotografías aéreas históricas y fotogrametría automatizada.

\section{Agradecimientos}

Este trabajo ha sido financiado por FEDER, Ministerio de Ciencia, Innovación y Universidades Agencia Estatal de Investigación, Proyecto CGL2017-84625-C2-1-R (CCAMICEM), Plan Estatal de Investigación, Desarrollo e Innovación Orientado a Retos de la Sociedad.

\section{REFERENCIAS}

Alfonso-Torreño, A., Gómez-Gutiérrez, Á., Schnabel, S., Lavado Contador, J. F., de Sanjose Blasco, J. J., \& Sánchez Fernández, M. (2019). sUAS, SfM-MVS photogrammetry and a topographic algorithm method to quantify the volume of sediments retained in check-dams. Science of the Total Environment, 678, 369-382. https://doi.org/10.1016/j.scitotenv.2019.04.332

Alfonso-Torreño, A., Gómez-Gutiérrez, Á., \& Schnabel, S. (2021). Dynamics of Erosion and Deposition in a Partially Restored Valley-Bottom Gully. Land, 10(1), 62. https://www.mdpi. com/2073-445X/10/1/62

Bakker, M. \& Lane, S. N. (2017). Archival photogrammetric analysis of river-floodplain systems using Structure from Motion (SfM) methods. Earth Surface Processes and Landforms, 42(8), 1274-1286. https://doi.org/https://doi.org/10.1002/esp.4085

Besl, P. J. \& McKay, N. D. (1992). A Method for Registration of 3-D Shapes [Article]. IEEE Transactions on Pattern Analysis and Machine Intelligence, 14(2), 239-256. https://doi.org/10.1109/34.121791

Brutto, M. L. \& Meli, P. (2012). Computer Vision Tools for 3D Modelling in Archaeology. International Journal of Heritage in the Digital Era, 1(1 suppl.), 1-6. https://doi.org/10.1260/2047-4970.1.0.1

Conesa-García, C. (1995). Torrential flow frequency and morphological adjustments of ephemeral channels in south-east Spain. En Hickin, E. J. (ed.), River Geomorphology (pp. 169-192). John Wiley \& Sons.

Conesa-García, C. (2005). Les "ramblas" du Sud-est Espagnol: Systèmes hydromorphologiques en milieu méditerranéen sec. Zeitschrift für Geomorphologie, 49, 205-224.

Cowley, D. C. \& Stichelbaut, B. B. (2012). Historic Aerial Photographic Archives for European Archaeology. European Journal of Archaeology, 15(2), 217-236. https://doi.org/10.1179/146195711 2Y.0000000010

Cucchiaro, S., Maset, E., Fusiello, A., \& Cazorzi, F. (2018). 4D-SfM photogrammetry for monitoring sediment dynamics in a debris-flow catchment: software testing and results comparison. The International Archives of the Photogrammetry, Remote Sensing and Spatial Information Sciences, XLII-2, 281-288. https://doi.org/10.5194/isprs-archives-XLII-2-281-2018

Eltner, A. \& Sofia, G. (2020). Structure from motion photogrammetric technique. En Remote Sensing of Geomorphology (pp. 1-24). https://doi.org/10.1016/b978-0-444-64177-9.00001-1 
Feurer, D. \& Vinatier, F. (2018). Joining multi-epoch archival aerial images in a single SfM block allows 3-D change detection with almost exclusively image information. ISPRS Journal of Photogrammetry and Remote Sensing, 146, 495-506. https://doi.org/https://doi.org/10.1016/j.isprsjprs.2018.10.016

Gómez-Gutiérrez, Á. \& Gonçalves, G. R. (2020). Surveying coastal cliffs using two UAV platforms (multirotor and fixed-wing) and three different approaches for the estimation of volumetric changes. International Journal of Remote Sensing, 41(21), 8143-8175. https://doi.org/10.1080/01431161. 2020.1752950

Gómez-Gutiérrez, Á., Schnabel, S., Berenguer-Sempere, F., Lavado-Contador, F., \& Rubio-Delgado, J. (2014). Using 3D photo-reconstruction methods to estimate gully headcut erosion. Catena, 120, 91-101. https://doi.org/10.1016/j.catena.2014.04.004

Gómez, C. (2014). Digital photogrammetry and GIS-based analysis of the bio-geomorphological evolution of Sakurajima Volcano, diachronic analysis from 1947 to 2006. Journal of Volcanology and Geothermal Research, 280, 1-13. https://doi.org/https://doi.org/10.1016/j.jvolgeores.2014.04.015

Guerin, A., Stock, G. M., Radue, M. J., Jaboyedoff, M., Collins, B. D., Matasci, B., Avdievitch, N., \& Derron, M.-H. (2020). Quantifying 40 years of rockfall activity in Yosemite Valley with historical Structure-from-Motion photogrammetry and terrestrial laser scanning. Geomorphology, 356, 107069. https://doi.org/https://doi.org/10.1016/j.geomorph.2020.107069

James, M. R. \& Robson, S. (2012). Straightforward reconstruction of 3D surfaces and topography with a camera: Accuracy and geoscience application. Journal of Geophysical Research: Earth Surface, 117(F3) . https://doi.org/https://doi.org/10.1029/2011JF002289

James, M. R. \& Robson, S. (2014). Mitigating systematic error in topographic models derived from UAV and ground-based image networks. Earth Surface Processes and Landforms, 39(10), 1413-1420. https://doi.org/10.1002/esp.3609

Lague, D., Brodu, N., \& Leroux, J. (2013). Accurate 3D comparison of complex topography with terrestrial laser scanner: Application to the Rangitikei canyon (N-Z). ISPRS Journal of Photogrammetry and Remote Sensing, 82, 10-26. https://doi.org/10.1016/j.isprsjprs.2013.04.009

Lowe, D. G. (2004). Distinctive Image Features from Scale-Invariant Keypoints. International Journal of Computer Vision, 60(2), 91-110. https://doi.org/10.1023/b:visi.0000029664.99615.94

Mertes, J. R., Gulley, J. D., Benn, D. I., Thompson, S. S., \& Nicholson, L. I. (2017). Using structure-from-motion to create glacier DEMs and orthoimagery from historical terrestrial and oblique aerial imagery. Earth Surface Processes and Landforms, 42(14), 2350-2364. https://doi.org/https:// doi.org/10.1002/esp.4188

Mölg, N. \& Bolch, T. (2017). Structure-from-Motion Using Historical Aerial Images to Analyse Changes in Glacier Surface Elevation. Remote Sensing, 9(10), 1021. https:/www.mdpi. com/2072-4292/9/10/1021

Nouwakpo, S. K., Weltz, M. A., \& McGwire, K. (2016). Assessing the performance of structure-from-motion photogrammetry and terrestrial LiDAR for reconstructing soil surface microtopography of naturally vegetated plots. Earth Surface Processes and Landforms, 41(3), 308-322. https://doi.org/10.1002/esp.3787 
Qin, R., Tian, J., \& Reinartz, P. (2016). 3D change detection - Approaches and applications. ISPRS Journal of Photogrammetry and Remote Sensing, 122(Supplement C), 41-56. https://doi.org/10.1016/j. isprsjprs.2016.09.013

Remondino, F., Spera, M. G., Nocerino, E., Menna, F., \& Nex, F. (2014). State of the art in high density image matching. The Photogrammetric Record, 29(146), 144-166. https://doi.org/https://doi. org/10.1111/phor.12063

Seitz, S. M., Curless, B., Diebel, J., Scharstein, D., \& Szeliski, R. (2006). A comparison and evaluation of multi-view stereo reconstruction algorithms. IEEE Conference on Computer Vision and Pattern Recognition, Nueva York.

Tonkin, T. N., Midgley, N. G., Cook, S. J., \& Graham, D. J. (2016). Ice-cored moraine degradation mapped and quantified using an unmanned aerial vehicle: A case study from a polythermal glacier in Svalbard. Geomorphology, 258, 1-10. https://doi.org/https://doi.org/10.1016/j. geomorph.2015.12.019

Ullman, S. (1979). The interpretation of structure from motion. Proceedings of the Royal Society B, 203, 405-426. https://doi.org/10.1098/rspb.1979.0006

Warrick, J. A., Ritchie, A. C., Adelman, G., Adelman, K., \& Limber, P. W. (2016). New techniques to measure cliff change from historical oblique aerial photographs and Structure-from-Motion Photogrammetry. Journal of Coastal Research, 33(1), 39-55. https://doi.org/10.2112/jcoastres-d-16-00095.1

Westoby, M. J., Brasington, J., Glasser, N. F., Hambrey, M. J., \& Reynolds, J. M. (2012). 'Structure-from-Motion' photogrammetry: A low-cost, effective tool for geoscience applications. Geomorphology, 179, 300-314. https://doi.org/https://doi.org/10.1016/j.geomorph.2012.08.021

Wheaton, J. M., Brasington, J., Darby, S. E., \& Sear, D. A. (2010). Accounting for uncertainty in DEMs from repeat topographic surveys: Improved sediment budgets. Earth Surface Processes and Landforms, 35(2), 136-156. http://www.scopus.com/inward/record.url?eid= 2-s2.0-77649140888\& partnerID=40\&md5=2ef93cc53edbd60a7e9a8e2fc3621789

Cómo citar este artículo:

Gómez-Gutiérrez, Á., Conesa-García, C., Ibisate González de Matauco, A., Pérez-Cutillas, P., Portillo-Grau, D., \& Segura-Méndez, F. J. (2021). Potencial de las imágenes aéreas históricas y la fotogrametría automatizada para elaborar modelos 3D de cauces efímeros mediterráneos y cuantificar cambios morfológicos. Cuadernos de Geografía, 107, 243-268.

https://doi.org/10.7203/CGUV.107.21119

\section{(C) (1) $\Theta \Theta$}

Este obra está bajo una licencia de Creative Commons Reconocimiento-NoComercial-SinObraDerivada 4.0 Internacional. 